\title{
Design of in-situ river kinetic turbines test facility in cold weather
}

\author{
Eric Bibeau, Shamez Kassam, John Woods, Ani Gole, Farid Mosallat (University of Manitoba) \\ Philippe Vauthier (UEK Corporation) \\ Tom Molinski (Manitoba Hydro)
}

\begin{abstract}
A river kinetic turbine testing program was initiated in collaboration with Manitoba Hydro and UEK Corporation in the Winnipeg River. The goal of this program is to determine if this renewable energy technology can economically generate power in remote and grid connected areas using river currents. Compared with other forms of power generation technology, kinetic turbines may be implemented with less infrastructure. Of importance is to implement engineering design solutions as part of the testing program subject to a fixed research budget, with operational and maintenance cost still unknown. This paper presents the design of the research project to develop a one-year demonstration of a UEK $60 \mathrm{~kW}$ turbine to assess its ability to produce power and determine annual operational and maintenance costs in cold weather applications. A research platform concept was developed to allow adjusting the turbine location to obtain different flow and turbulence conditions and be able to pull the turbine out of the water to perform maintenance work, all at minimal cost. A low cost anchoring system was also put into service to secure the research platform. Instrumentation of the turbine was designed to obtain power, voltage, pressures, flow, turbulence, turbine loads and vibration. In addition, a remote sensing system was implemented to monitor the turbine performance and condition. Innovative approaches to design and operational logistics may make kinetic turbine technology an economically efficient solution.
\end{abstract}

\section{An introduction to kinetic turbine technology}

Kinetic hydropower river applications involve the use of underwater turbines in relatively high-velocity river current. The turbines convert the kinetic energy in a river to generate electrical power, and may be relatively inexpensive without the requirement for dams or powerhouses. Installations are situated at strategic points along a targeted river where the land formation provides a natural flow restriction, resulting in locally high velocities. At these locations, one or several turbines are installed beneath the surface of the water for the purpose of electrical power generation. Multiple units can be used to generate more power but they cannot rival the power available and low cost from conventional hydro. Furthermore, with no associated reservoir or spillway, kinetic hydropower has minimal environmental impact. Thus, kinetic hydropower can supplement traditional hydro production. The term "kinetic hydropower" is used to differentiate this technology from run-of-river and small hydropower power plants which require the construction of dams or powerhouses, and rely on potential energy. The modular nature of kinetic hydropower leads to a scalable energy output but with limited decrease in capital cost per kWe for multiple units. Finally, the availability of continuous river flow leads to steady energy production, thus reducing the need for ancillary services like regulators and load following, although significant year to year flow variations need to be taken into account.

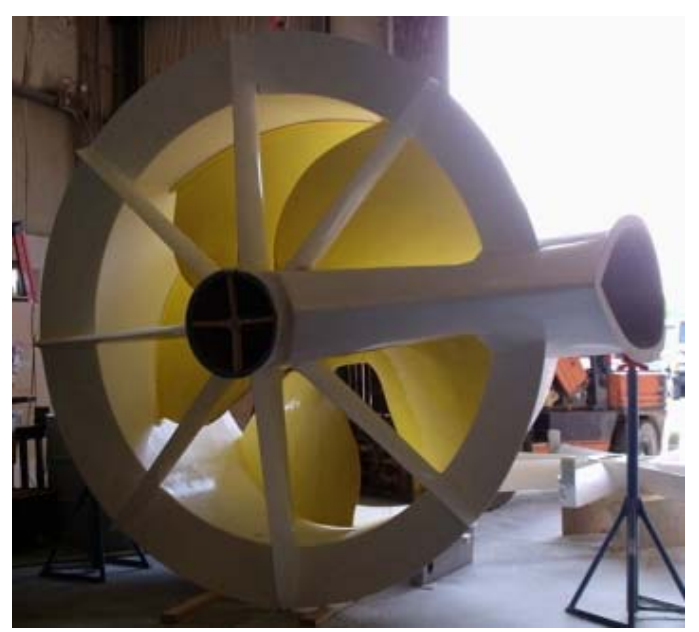

Figure 1: UEK $60 \mathrm{~kW}$ kinetic turbine $(8 \mathrm{ft}$ rotor diameter)

Manitoba is well suited for kinetic hydropower applications, as a significant part of North America's rainfall drains into the Hudson Bay passing through Manitoba's river system. It is therefore important for provinces like Manitoba to understand the potential of this technology in cold climate applications. Kinetic river turbines have not been adequately tested over a significant period of time, especially in cold weather river applications. To help commercialize this 
renewable energy technology, a partnership between Manitoba Hydro, the Underwater Electric Kite (UEK) Corporation from Maryland, and the University of Manitoba was developed to research and evaluate the effectiveness of a 60-kW UEK kinetic underwater turbine (120-kW when twined for commercial application) that uses water flow currents to generate electricity.

Kinetic hydropower allows the possibility of off-grid power generation for remote communities which can produce power from locally available rivers without the need for major construction, road access and heavy equipment. This technology can and lower emissions (PM, SOx and NOx) from diesel generators that would now act as a back-up supply or operate at much reduced base loads. It can enhance the local economy, and reduce the overall power production costs in remote locations. Such generation can enhance grid stability when the turbines are located at the weak end of the distribution grid, provide feeder voltage support, and can possibly reduce outages in certain areas. Kinetic turbines offer relatively continuous operation, an advantage over technologies such as wind and solar sources, which are intermittent. Evaluation of this technology is made particularly more difficult because of the cold winter climate and spring ice run-off conditions in Manitoba. This project will provide data on the operation and cost of kinetic hydropower. Long-term testing of kinetic hydropower in cold winter climates is an important step towards commercialization of this emerging hydro technology.

Kinetic turbine technology has the potential to provide cost-effective generation of electricity without the use of reservoirs in circumstances when a suitable head does not exist but strong stream flow is available. Potential sites which meet the criteria needed for kinetic turbine deployment are potentially numerous in Canada. The demonstration project may show that with low capital cost, consistent power production, and a source of renewable energy with minimal environmental impact, kinetic turbines may be an attractive option for electrical power production.

\section{The UEK project}

Preparations are underway and progress is being made in anticipation of a one year test of the kinetic turbine which will be placed in the river at Pointe Du Bois, Manitoba. A simple, low cost anchoring system was devised and already implemented on site. The anchor design minimized the financial commitment to the construction of the infrastructure and its impact on the local ecology. A retractable turbine, housed on a research boat, is located on the Winnipeg River where the flow velocity is between 2.0 to $2.6 \mathrm{~m} / \mathrm{s}$. At that location, there is a significant amount of turbulence. In order to get a range of velocities and turbulence levels in which to test the turbine, its location can be varied. Over the year, close attention will be paid to the operational costs by continuously monitoring the turbine. An automated system was developed to assist in monitoring and collecting research data. For monitoring purposes, autonomy is important to keep operational costs low. The overall goal of this project is to demonstrate that this technology can be cost effective in producing clean, consistent and reliable power.

\section{Infrastructure}

Kinetic turbines can be potentially implemented with structural supports far less extensive than any other power generating system currently in use. This research initiative derived and employed some simple solutions that keep costs down and environmental protection a priority. A major consideration regarding the application of Kinetic Turbine technology in a fast flowing river is the mounting of the unit at a suitable depth - without a fixed structure to lower costs. Also, the reliable avoidance of significant ice segments, logs and other debris must be considered in the deployment of these systems.

Three of the key attributes of the Canadian Shield rivers under consideration for this application are a year-round continuous flow, a solid rocky bottom and relatively sediment-free water. While many waterways within Manitoba have suitably high seasonal flow rates, those within the Red River valley have muddy bottoms which result in ever-changing river bottom configurations - as well as suspended particles (which would be expected to be abrasive). At our test site on the Winnipeg River and many probable locations to the North, the river passes through significant rocky areas, typically granite. These river channels are fixed, and as a result of changes in elevation and width they can maintain an average velocity of $1.5 \mathrm{~m}$ or greater at various locations, which is sufficient to inhibit cover-ice formation.

The formation of ice, and in particular the passage of large fractured segments during spring break-up are serious considerations for the mounting system under consideration, with hopes that a turbine can provide year-round power even through the spring break-up. Various methods have been considered during the 
development stages, including an artificially created 'reef' to anchor the Turbine to the bottom, and cable retention from the shoreline. In the first case, initial modeling showed that it may be possible to 're-shape' the flow over and around the 'reef' to optimize it for Turbine interaction. It would require the placement of fabric 'bags' at the river bottom, into which concrete would be poured or heavy anchors deployed. Even during a low-flow condition, this would not be a simple installation, and environmental aspects within pristine waterways would be a major consideration.

After reviewing the results of spring break-up of ice in various rivers the impact of large segments of ice would ply against shore cables, and even if it did not cause cables to fail, the angle and direction of the turbine would most likely be affected. The solution decided upon was to anchor the turbine to the river bottom with several rods, drilled and set into the rock using a cement compound. Using this method, the turbine can be positioned at any height within the water column by adjusting turbine tilt angle. Also, with the exception of a suitable water depth, the turbine can be placed anywhere across the river, and therefore an optimal location can be selected - without the necessity to be close to shore. Using this method will result in a minimized profile for floating ice and debris and create power without a visible disruption to the environment.

In order to place the river bottom anchors in a specific location, barge anchor points were established on both sides of the shoreline using $25 \mathrm{~mm}$ diameter steel rods drilled and fastened into place with cement. A flattop barge was fitted with: a compressor (for drilling and pneumatic winches), three 2-ton positioning winches and a drill rig. The positioning winches were located at the 'downstream' end of the barge, and $1 / 2$ " steel cable ran through a pulley at each 'upstream' corner and out to the anchor points on the shoreline. Using this system, the barge could be located and held fixed at any position across the width of the river, by adjusting the line lengths.

Figure 2 shows how the two cable positioning system provides a full range of 2-D motion for locating the barge. A tug boat was used to move the barge back and forth from the dock to the site, and two open boats with outboard motors were towed along side for emergency back up. Drill rods were fitted with bits, and the bit end was welded onto each rod. Once the rods were embedded into the rock they were sacrificed and left in the rock to act as attachment points. The rods were hollow, so that a grout mixture could be pumped into the hole, though the rods, filling up the void created in the rock and the rod itself.

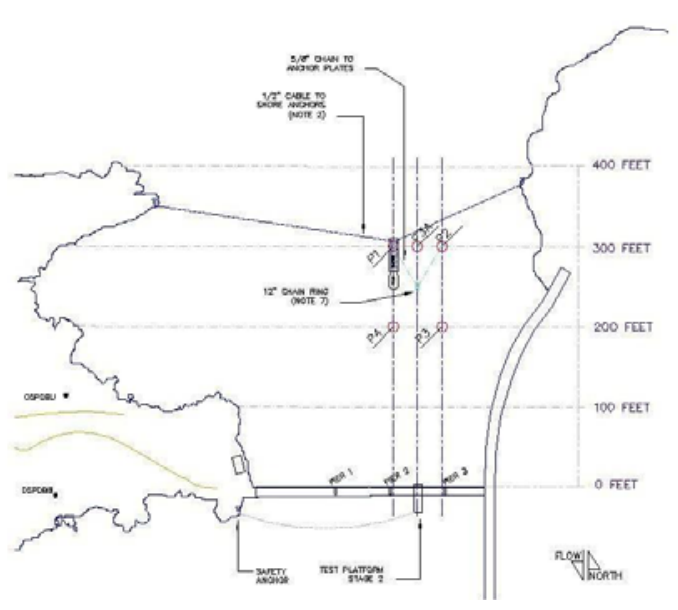

Figure 2: Anchor drilling method

Since the rods were in 10 feet in length, and the water was over 20 feet deep, the drill bits were unable to gain sufficient initial bite - due to a wobbling of the shaft. A heavy drilling plate was designed, with a collar, which was lowered down to the bottom along with the drill rod, in order to hold the rod in place and start the drill hole. Figure 3 shows the overall schematic of the system. Once the rods were in place and filled with grout, a tethered scuba diver was lowered to the bottom to cut off the excess rod and place a steel plate over the rods. Two nuts were threaded onto the rods, in a lock-nut configuration. To these anchors, 5/8" chain was fastened using threaded pin shackles. The initial design did not require a scuba diver but cold water prevented the sacrificial drill rod from unlatching from the drill stem. Two anchors pointes were placed perpendicular to the river's flow direction, and 30' of 5/8" chain was attached from each to a center yolk, from which the turbine will be supported. Figure 4 shows an underwater photo of the final anchor.

In order to be ready for delivery of the turbine in the summer of 2007, the anchor points described above were installed in October of 2006. The above technique constitutes a unique installation method, and required concurrent design input to meet the original design objectives. The anchoring system of the turbine required a minimal amount of structural components and labour to put it in place. This reduced capital costs and minimized environmental impact. The use of a barge with 30 feet legs would have 
significantly simplified the anchoring but was too costly.
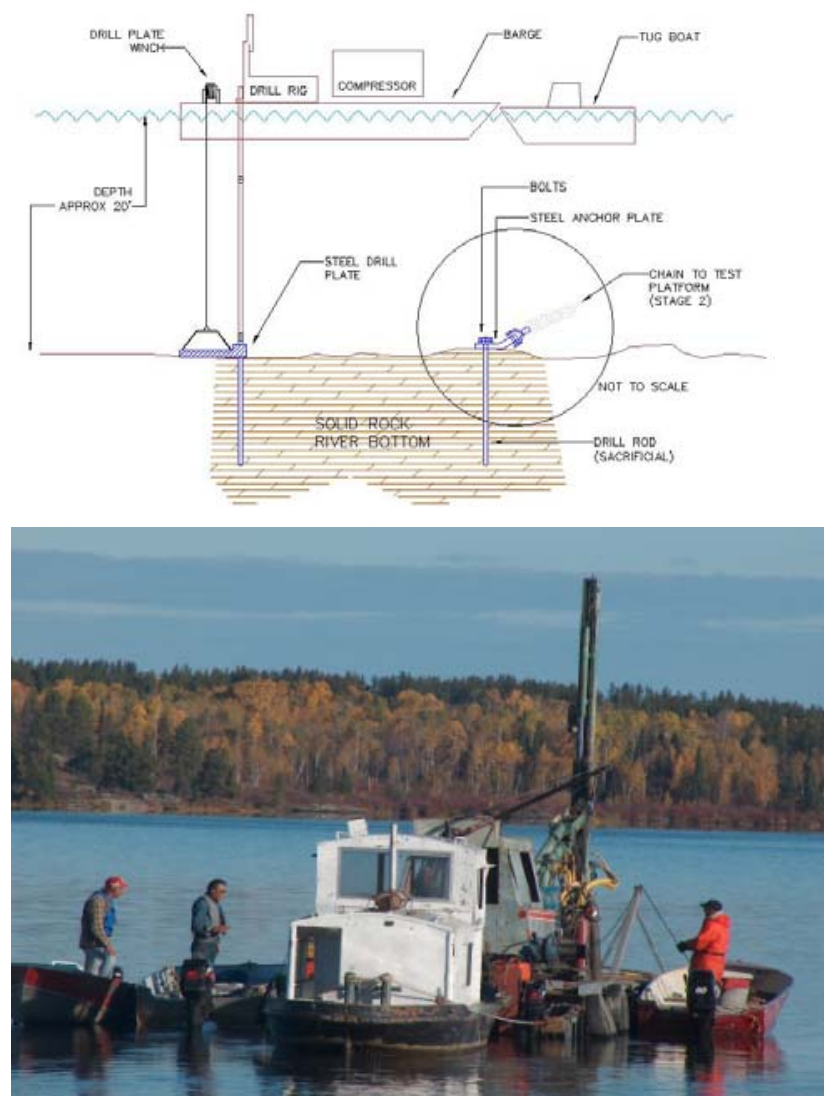

Figure 3: Anchor drilling schematic and drill rig

\section{Turbine Positioning}

The location of the turbine was made variable in order to test its capability in a range of flow speeds as well as a range of turbulence levels. The turbine will be located near a foot bridge upstream of a hydro power plant. At this location, the river reaches a high flow velocity. To test a range of flow conditions, an adjustable positioning system needed to be designed.

The solution is to have a system of steel cables 200 feet in length to anchor the turbine to the river bed. By using three connected cables rather than one long continuous piece, the installation and manipulation of cable lengths become more manageable. Two hundred feet of continuous cable will weigh over 600 $\mathrm{lb}$ and require additional equipment to handle.

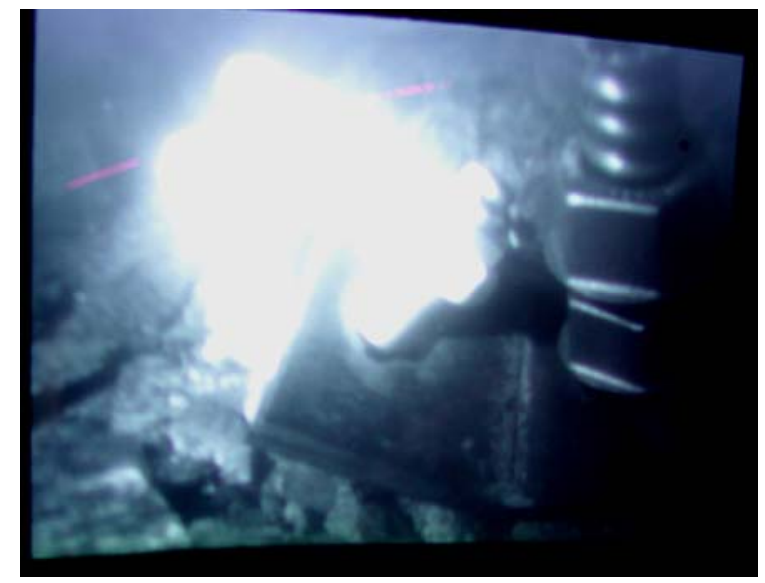

Figure 4: Underwater view of anchor

Another benefit of having links of cables is that when moving the turbine by distances greater than the length of one link, that link may be bypassed, speeding up the adjustment time. The design's primary objective was to minimize downtime and make changing the distance simple. One link will consist of 5/8" chain; the rest will be $1 \frac{1}{1 / 4}$ " steel wire cables. The chain will be held at the required length by a safety hook, connected to a shackle at one end and hooking into the chain at the other. The chain length will be used for small adjustments in the turbine position by simply rehooking the safety hook higher or lower along the chain.

\section{Research Platform}

The turbine is installed on the platform / boat in order to launch the equipment, operate monitoring stations and accomplish maintenance or alterations if necessary. A mechanism was drawn up and built in fibreglass by UEK in their Annapolis, MD workshop. The boat itself was sheathed in fibreglass since the original aluminium hull could possibly become heavily weighted with ice during the winter months. This work also presented unique challenges in its application. To eliminate as much as possible the cooling transfer from the running water, an insulating "skin" was installed around the hull that is not bonded to the aluminium hull but suspended from a heavy frame surrounding the boat about thirty centimetres above the water line. At that point, the skin is bonded with a sealant into the frame all around the boat. With this method it is hoped to be able to avoid icing problems in a super-cold water environment (Frazil conditions). 
The turbine is fixed onto the boat by a pivoting mechanism. This mechanism allows the turbine to be retracted from the water using a hydraulic system for maintenance work or relocation. This system offers advantages that may save time and potentially costly complications during testing. By allowing the turbine to be lifted onto the boat, re-positioning the turbine is as easy as moving the boat and adjusting the support cables. When moving the turbine's location, the turbine is lifted out of the water after the boat is moved forward so that the chain may be brought onboard. A drawing of the boat, turbine and trash rack can be seen in Figure 5.

Ahead of the boat, a V-shape boom is secured to the anchor and is made of foam filled PVC pipes. From the pipes, aluminium bars hang under the water to support a steel mesh. This mesh, extending a few feet under the water line, acts as a deflector for floating debris. The boom floats upstream of the research platform and protects the turbine from being hit by floating logs or any slabs of ice which may drift down the river in the spring time.

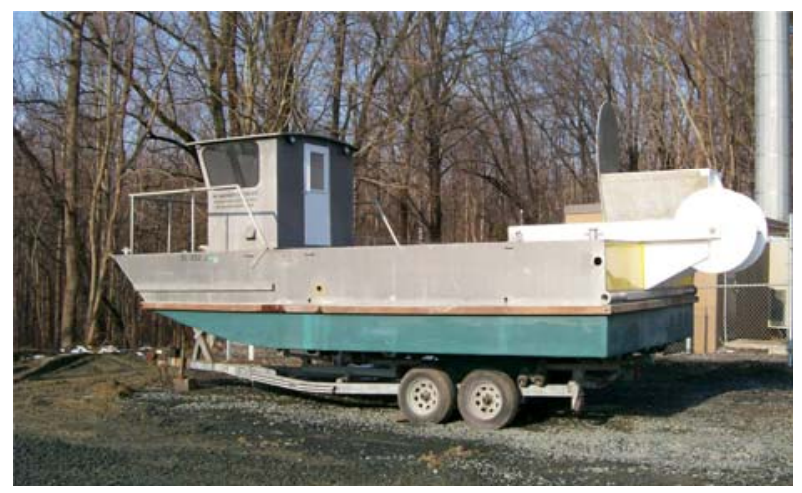

Figure 6: Boat without turbine

Figure 6 depicts the positioning of the boat and the boom. It can also be seen from this figure how the turbine is connected to the boat.

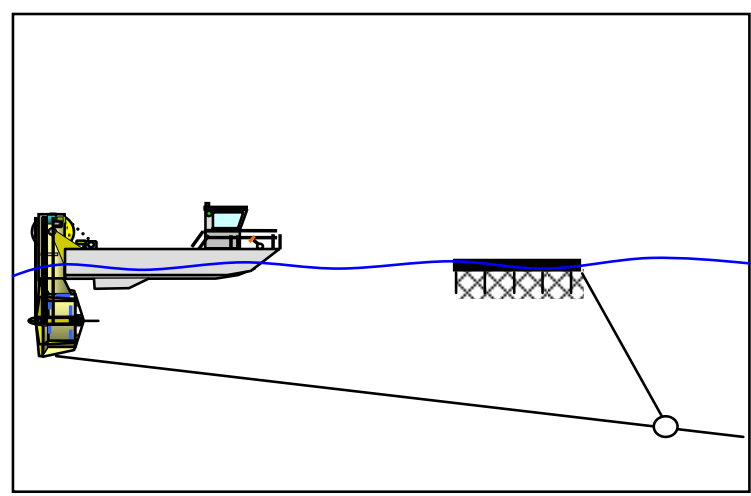

A second cable connection acts as a backup safety system. Connecting directly to the one side of the turbine, it is anchored to shore near the walk bridge shown in Figure 2. If the main support cable breaks and the boat is dragged towards the power house downstream, this cable will catch the boat and swing it into a safer, low velocity bay.

This anchoring design uses minimal materials, resulting in savings with respect to capital costs. A basic and capable solution was found to solve the numerous challenges posed by putting a turbine in the middle of a high velocity river flow. The minimal structure also translates into a significantly reduced impact on the local ecology, thus preserving the environment and simpler decommissioning.

\section{Data Acquisition / Monitoring System}

The economic viability of the kinetic turbine technology rests in its potential to deliver reliable power with minimal operating costs. By minimizing the manual overseeing of daily operation, the costs for supporting this technology can be reduced. Automation is the key for making kinetic turbines economically attractive. The test turbine is fitted with a variety of sensors that will be used to assess its performance. A data acquisition system is employed to gather the data given by the numerous temperature, pressure, load, and vibration sensors. This data is gathered at a uniform frequency, but it can be adjusted to monitor different channels at different sampling rates. At regular intervals throughout the day, the data is complied and reviewed by software developed in house. The software replaces the need for manual interpretation of the data. Each data entry from every sensor is assessed and compared to pre-determined alarm values. Once an alarm is breached, the system alerts the operator of the issue at hand for his intervention. Thus this system will only require the attention of an operator if a problem is detected. The system is designed for unattended operations and uses the internet to transfer all required information.

The way in which this system uses the internet allows control of the system wherever the operator may be. The research platform is fitted with cameras which broadcast from a server computer to a remote client. The client software can be downloaded and accessed from any computer terminal which is connected to the internet. Not only will the operator be alerted to any problems detected by the sensors, but be able to access

Figure 5: Boat and boom positioning 
the data online and view video of the site in real time to make the best decision with the information.

Figure 7 shows the fish louver to prevent fish from entering the turbine and the flow guide vanes to improve turbine efficiency. A separate study will be conducted in the future as to the environmental impact on fish mortality. Figure 8 shows the test site during winter.

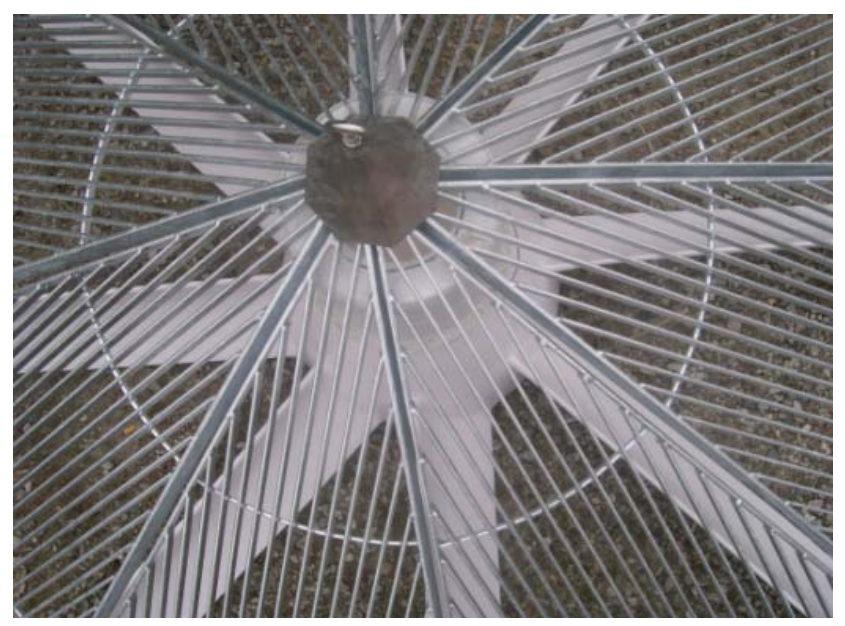

Figure 7: Fish louver and flow guide vanes

\section{Concluding remarks}

Kinetic turbine technology can be deployed in many locations. Remote areas will benefit the most since they may produce clean, renewable energy. Off grid locations near fast flowing rivers may become attractive applications to displace diesel generation. This technology has the ability to reach many communities all over the world. By exploiting the benefits of the internet, multiple turbines deployed in remote regions can be monitored by a minimal staff in an office anywhere. Innovative software and logistical procedures can minimize operational costs to a point where kinetic turbines may become an attractive power generating solution.

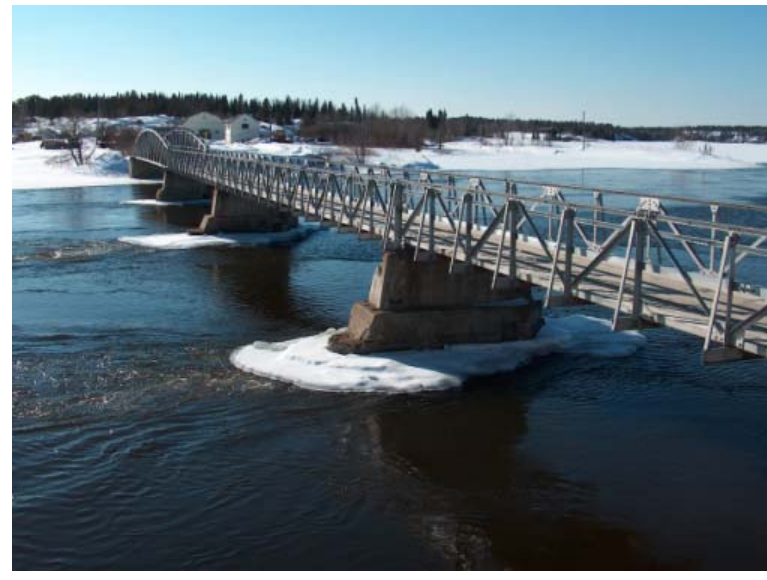

Figure 8: Open water in winter time at test site 